\title{
Tsafon
}

Revue d'études juives du Nord

$72 \mid 2016$

Juifs, Israéliens, dans la littérature française et israélienne

Sébastien Durand, La gradation macabre, 1940-1944. L'aryanisation des " entreprises juives " girondines

\section{Danielle Delmaire}

\section{OpenEdition}

\section{Journals}

Édition électronique

URL : https://journals.openedition.org/tsafon/481

DOI : $10.4000 /$ tsafon.481

ISSN : 2609-6420

Éditeur

Association Jean-Marie Delmaire

Édition imprimée

Date de publication : 1 décembre 2016

Pagination : 174-175

ISSN : $1149-6630$

Référence électronique

Danielle Delmaire, « Sébastien Durand, La gradation macabre, 1940-1944. L'aryanisation des « entreprises juives » girondines », Tsafon [En ligne], 72 | 2016, mis en ligne le 31 mai 2018, consulté le 24 juin 2021. URL : http://journals.openedition.org/tsafon/481 ; DOI : https://doi.org/10.4000/tsafon.481

Ce document a été généré automatiquement le 24 juin 2021.

Tsafon. Revues d'études juives du Nord 


\title{
Sébastien Durand, La gradation macabre, 1940-1944. L'aryanisation des " entreprises juives » girondines
}

\author{
Danielle Delmaire
}

\section{RÉFÉRENCE}

Sébastien Durand, La gradation macabre, 1940-1944. L'aryanisation des "entreprises juives » girondines, Bordeaux, éditions Memoring, 2016, 195 p., $22 €$.

1 Le livre paraît grâce à une maison d'édition régionale qui ne lésine pas sur la qualité matérielle : papier épais et belle présentation paginale, agrémentée d'illustrations. Mais le contenu importe aussi.

2 L'éditeur a eu raison de faire paraître cette étude qui, sans doute, provient partiellement d'une thèse puisque l'auteur est docteur depuis la soutenance qui eut lieu le 8 décembre 2014. La thèse étudiait les entreprises de la Gironde occupée. L'auteur a accompli un sérieux travail de recherche scientifique en fouillant dans les archives nationales (série J 40 du Militärbefehlshaber in Frankreich et J 38 sur l'aryanisation des entreprises dites juives), ainsi que dans la série $\mathrm{W}$ des Archives départementales de la Gironde, auxquelles il a ajouté un dépouillement des archives municipales. La bibliographie mentionne les récents travaux de Philippe Verheyde (1999-2004), de Jean-Marc Dreyfus (2003-2015), de Tal Bruttmann (de 2004 à 2012), de Martin Jungius (2012), ainsi que l'indispensable rapport de la Mission d'étude sur la spoliation des Juifs de France rédigé par Antoine Prost et alii (2000). Tsafon peut regretter que cette bibliographie oublie son numéro 5 hors-série sur la «Spoliation des Juifs et des Tsiganes dans la Zone Rattachée et en Belgique pendant la seconde Guerre mondiale ", sorti en novembre 2012 ; il rassemble les interventions de Jean-Baptiste Gardon, Claire Zalc, Tal Bruttmann, Laurence Schram, Jean-Philippe Schreiber, Monique Heddebaut 
(pour les Tsiganes) et livre trois témoignages d'enfants de commerçants juifs spoliés, dans le Nord. Cet ouvrage pouvait aussi servir à l'auteur.

3 Le cheminement du livre suit le processus de spoliation mis en place par les nazis: définir qui est juif et recenser les juifs, pour mieux leur interdire leurs activités professionnelles et enfin pour les voler en confisquant leurs entreprises et en les liquidant ou en les vendant.

4 Le processus s'appuie sur une série d'ordonnances allemandes (27 septembre 1940 et 26 avril 1941) ainsi que sur la loi française du 2 juin 1941. Très rapidement, en moins d'un an, comme le soulignait l'historien Étienne Dejonghe dans son introduction au $\mathrm{n}^{\circ} \mathrm{de}$ Tsafon cité ci-dessus, la juridiction est complète pour faire disparaître de l'économie française toute présence juive.

5 L'initiative du "vol organisé » (M. Jungius) provient des Allemands mais l'administration du Gouvernement de Vichy n'est pas en reste. À commencer par la préfecture où le secrétaire général, Maurice Papon, est à l'œuvre : « la préfecture est en première ligne » (p. 39). Le Commissariat général aux questions juives créé le 29 mars 1941 aidé du Service de contrôle des administrateurs provisoires (SCAP) supplée les administrations occupantes. Quant aux chambres de commerce, les syndicats patronaux ou encore les officines de notaires, ce sont autant de structures qui participent à la curée, souvent avec cynisme. À juste titre, l'auteur les qualifie de "collaboratrices". Dans ce pillage, s'exprime librement un antisémitisme démesuré voire passionné. Les convoitises et la concurrence sont satisfaites.

6 L'impuissance des propriétaires juifs est totale mais il leur reste des échappatoires: l'auto-aryanisation en cédant rapidement leurs parts à des collaborateurs aryens, ceux-ci pouvant être complices d'une vente fictive (voir aussi les témoignages recueillis dans le $n^{\circ}$ de Tsafon). D'autres ont préféré la fermeture volontaire quitte à supprimer des emplois et à perturber l'économie locale.

7 Le pillage ne dépouille pas les juifs de leurs seuls commerces ou entreprises : des immeubles, des avoirs en banque, des bijoux, du mobilier, des œuvres d'art et des biens de toute nature sont confisqués et vendus.

8 L'ouvrage s'attarde sur deux exemples particuliers: la maison Castelle et surtout le domaine viticole des Rothschild qui est aryanisé et des bouteilles de grande valeur, puisque datant de la fin du XVIII siècle, sont confisquées, certaines étant l'objet de convoitise des Allemands et des Français qui d'ailleurs rivalisent dans la spoliation.

9 L'ouvrage se termine par quelques pages de bilan, un peu trop léger, me semble-t-il, et les difficultés rencontrées par les rescapés du massacre et de la spoliation, au lendemain de la guerre, sont abordées allusivement. Or certains petits commerçants durent attendre quatre à cinq ans pour recouvrer leurs biens.

10 La disparition des entreprises et des biens des juifs participe à la Shoah, d'abord parce que les spoliés ont bien souvent été déportés et ne sont pas rentrés ou bien, s'ils ont pu se cacher, ils ont perdu leurs avoirs et leurs revenus par cette spoliation. L'aryanisation des entreprises dites juives va de pair avec l'extermination. La disparition des propriétés est même une conséquence directe de la disparition des personnes.

11 Après la guerre, les historiens se sont attelés à la recherche sur l'extermination des personnes. Le sujet s'imposait par son côté tragique. Et ce n'est que tardivement que la disparition des biens intervient dans le champ de recherches. Il faut en effet attendre la fin des années 1990 pour que des travaux soient publiés. Sans doute la commission 
dirigée par l'historien Antoine Prost a-t-elle suscité la curiosité des chercheurs. Voilà un livre qui participe pleinement et heureusement à cette historiographie 